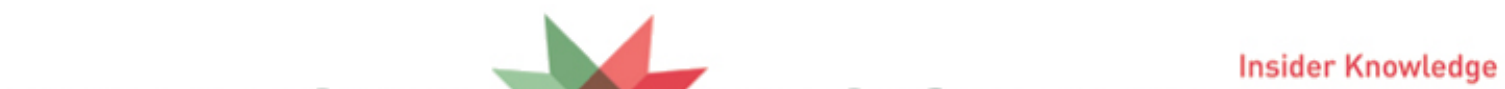

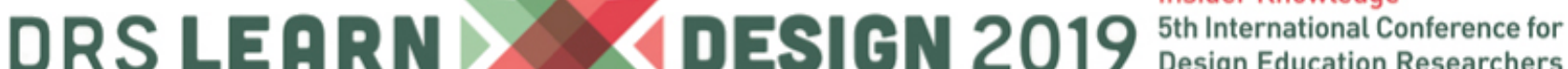 \\ Design Education Researchers \\ 9-12 July 2019, METU, Ankara
}

\section{UX Modelling in Design Education: Methods, Processes and Examples}

\author{
Gülşen TÖRE YARGIN \\ Middle East Technical University, Department of Industrial Design \\ METU/BILTIR-UTEST Product Usability Unit \\ tore@metu.edu.tr \\ Aslı GÜNAY \\ Middle East Technical University, Department of Industrial Design \\ METU/BILTIR-UTEST Product Usability Unit \\ agunay@metu.edu.tr
}

Sedef SÜNER-PLA-CERDÀ

TED University, Department of Industrial Design

sedef.suner@tedu.edu.tr

doi: 10.21606/learnxdesign.2019.15129

\begin{abstract}
This paper presents user experience (UX) modelling as an educational goal, outlining and grounding on the growing need for trained UX professionals and opportunities for expanding design expertise in this direction; and emphasises the importance of developing a sustained teaching agenda to address the requirements of the contemporary professional practice. After an overview of use and types of models in UX, we offer UX modelling as a teaching tool to equip design students with the theoretical and applied knowledge and skills relevant in user experience research (UXR) and design process. From this point of view, we demonstrate how we utilised UX modelling in graduate level industrial design education and illustrate examples from student works. We discuss applications of this approach by offering the use of modelling as a tool for analysing and communicating user experiences, as well as an apparatus to shape the process of transferring user insights into design implications.
\end{abstract}

Keywords: user experience; design education; industrial design; user research; UX modelling

\section{Introduction}

As the digital products and services have become more pervasive in daily lives, there has been a shift from objectfocused towards a holistic, experiential approach in design fields. The experiential approach is typically described by how it differs from traditional usability. For example, Jordan (1999) recommends a rather holistic view towards userproduct interaction beyond instrumental aspects by taking into account hedonic features including emotions, expectations and dreams of the users. Similarly, according to Hassenzahl and Tractinsky (2006), usability deals with task-related, instrumental dimensions of interactions with a product or system, while user experience as a paradigm expands this by tackling also with less explicit issues such as meaning and values attached to products by users. This naturally brought about an interest to conceptualise this complex nature of UX by taking a more holistic lens in an 
effort to develop design strategies to mediate potentially positive and meaningful experiences (Fulton Suri, 2003). Therefore, it is required to expand the focus of inquiry from the instrumental interactions between the product and the user towards adopting a holistic approach, which takes into account subjective, social and contextual factors, thus placing the object of design into a complex system of users, products/services/systems and environments.

In the meantime, the disciplinary growth of UX has gained impetus with an increasing number of UX conferences, workshops, seminars and publications, as well as communities such as the Interaction Design Association and User Experience Professionals Association. Concordantly, UX has become an emerging profession in a diverse range of industries, so much so that specialist positions for UX designers, researchers, engineers and writers are being opened up in the job market (Gonzalez, Smith \& Youmans, 2017). Nevertheless, a common and sustained educational agenda has not been achieved to train the future UX professionals within academia. For example, UX education programmes are mostly unavailable, which leads to individual efforts of self-taught professionals (Getto, Potts \& Salvo, 2013). Thus, in line with the increasing demand from industry for job-ready UX specialists, online UX courses, internship programmes, workshops and camps begin to emerge to address the immediate necessity for practice-ready UX professionals.

The challenges of developing a shared agenda for teaching UX lies beneath the transdisciplinary nature of the field. As it holds true that UX as an academic discipline and professional practice has evolved within a myriad of fields, it may raise managerial issues as to who "owns" or teaches the course (Getto, Thompson \& Saggi, 2016), as well as the content and structure of it. Nonetheless, various design and technology disciplines have been putting effort to integrate UX awareness and skills into curriculum, including human-computer interaction (Faiola \& Matei, 2010), industrial design (Budd \& Wang, 2017), human factors (Gonzalez et al., 2017), interaction design (Bødker \& Klokmose, 2012), and technical communication (Getto \& Beecher, 2016), naturally focusing on expanding the traditional boundaries of knowledge and skills attributed to their own field. Despite this diversity in disciplinal approaches, user research is recognized as a central skill embedded in the UX design process, and inarguably one of the highly-favoured skills shared by many disciplines. Particularly, the importance of teaching qualitative methods of user research is emphasised, including ethnography (Faiola, 2007; Hanington, 2010), requirements gathering (Getto et al., 2013), and participatory methods (Hanington, 2010).

Given the centrality of user research in this transdisciplinary UX practice and to correspond to the aforementioned educational needs, our teaching approach and efforts as industrial design educators have been primarily focused on introducing a more specific approach-user experience research (UXR) ${ }^{1}$ into graduate curriculum. The ability to individually plan, execute and communicate UXR is an important skill in the UX process, which is highly valued by not only professionals (Gonzalez et al., 2017), but also students and educators (Churchill, Bowser \& Preece, 2016). From this point of view, our teaching efforts have focused on strategies to equip design students with the knowledge and skills to independently plan, conduct, analyse and communicate UXR. Through this process, the aim is to build UX models and we called this process "UX modelling". We propose UX modelling as a resourceful tool to not only introduce students with a theoretical understanding about what UX is, but also guide them towards acquiring skills in making sense of user data, visualising insights and transferring them into design requirements, thereby bridging theory with practice.

Considering these, the aim of this paper is to present UX modelling as an educational approach to train designers in UXR and discuss the potentials of using models in UXR education by illustrating how models are constructed and used by students. Accordingly, in the rest of the paper, we first discuss the functionality of models in UX and introduce types of UX models. Then we present our efforts to integrate UXR into graduate level industrial design education with the UX modelling approach. After that, resulting models are illustrated from student projects. Finally, the paper is concluded with discussions on the functions and use of UX models in design education together with limitations and future directions.

\footnotetext{
${ }^{1}$ At this point, we feel the need to indicate our stance towards the terms "user research" and "user experience research (UXR)". Although both terms cover same or similar methodologies and practices, user research is more generic and inclusive in that it also covers the approaches and methodologies that focus on user-product interaction before the emergence of the term UX. In this text, the term "user research" is used to denote a more generic approach for exploring, investigating and evaluating user-product interaction, whereas UXR refers to a more specific approach we adopted in this course and the historical underpinnings of which are briefly reviewed in the introduction of this paper.
} 


\section{Modelling in User Experience}

In broader terms, modelling is an essential part of understanding complex systems and processes. That is the reason why they play a crucial role in the conception, dissemination and recognition of knowledge (Gilbert, 1991; Gilbert, 2005). Gilbert (2005) summarizes the function of a model as a tie between reality and scientific theory because models may pertain to the simplifications and abstractions of the reality as observed or to the idealisations of a possible reality. According to Deutsch (1952), models are based on patterns of the past (i.e. behaviours of a social group), organised through a judgement of relevance, which otherwise would be virtually impossible to grasp directly, and give the interpreter the predictive power to describe further impact. So, no matter what the specific scientific domain at issue is, models are powerful to make abstract and/or complex concepts visible and supposable. Looking from an extended perspective-i.e. involving different meanings and appearances of models in different branches of science such as physics, chemistry, biology, geography, and so on-models can portray abstract/fictional concepts or material/physical things (e.g. magnetic field vectors or structure of a bridge); can present independent scientific entities, parts of larger systems, or the whole system (e.g. an atom, an atom in a molecule, atoms in a certain material); may have a larger or smaller scale than the scientific entity that it stands for (e.g. a bacteria or a human body); and may depict a snapshot of an event or a longer process (see Caws, 1974; Giere, 1999; Gilbert, 2005; Frigg \& Hartmann, 2018). Hereby, models, and inherently visualizations, are central to science education and learning as well in order to analyse, organize, teach and present (Frigg \& Hartmann, 2018), as they facilitate the comprehension and navigation between scientific concepts, meanwhile allowing to focus on major blocks of the research topic rather than less significant parts.

The benefit of the use of models in UX is evident in its multidimensional, dynamic and complex nature. The motivation behind the effort to better comprehend the aspects of experience is to come up with design strategies that mediate experiences which are potentially positive and meaningful for users (Fulton Suri, 2003). Therefore, making sense of such a complex phenomenon is challenging, yet crucial for developing and improving products and services relevant to that experience. Investigation of UX through modelling can be a resourceful approach in order to discover, understand and communicate; as well as serving as an actionable medium for transferring insights into ideation.

The approach to modelling can be qualitative, as much as quantitative as in measurement models (such as the ones described in Law \& van Schaik, 2010). Our approach to UX modelling in education is manly qualitative, with a strong emphasis on understanding the underlying paradigms of the experience (which are inherently rich, multidimensional and even sometimes latent), such as user concerns, behavioural patterns, impact of contextual factors, interactions afforded by products/services/systems and so forth, which eventually constitute the experience holistically. Such a holistic understanding can be obtained by utilising qualitative research methods including interviews, observations and generative techniques, and requires visualisation skills to communicate insights beyond statistical modelling (Gonzalez et al., 2017).

\section{Types of UX Models}

Given the multifaceted nature of UX, a UX model can focus on representing particular aspects of the experience at hand. One approach is to represent the activities and works of users, which can capture the work of users, their networks, involved organisations and environments in diagrams or such visualisations. These representations include work models in contextual design, such as the flow model, the cultural model, the sequence model, the physical model and the artefact model, as categorised by Holtzblatt, Wendell and Wood (2004). Models representing the user can be in the form of either data-driven or inspirational personas (Pruitt \& Adlin, 2006), as well as task-based user segments based on mental models (Young, 2008). They are important to humanise design focus, consummate scenarios, and aid forming an estimate of dealt user behaviours and practices (Hanington \& Martin, 2012). Especially, data gathered as a result of ethnographic research or other generative techniques focusing on daily experiences of the user are of great importance to understand the user, performed interactions, and contextual frame, upon which activities and works or users might be mapped.

Models depicting the concepts and their relations are related more to the mental content and conceptions of users. Specialised interview techniques may allow formation of specific types of models representing the concepts and their relations. For example, analysis of laddering interviews can be visualised as hierarchical value maps (HVM), a specific format illustrating the relationships between the elicited product attributes and attached meanings, hierarchically organised as attributes-consequences-values (Reynolds \& Olson, 2001; Miles \& Rowe, 2004). Repertory Grid Technique (RGT) can be analysed and visualised as cross-impact analysis (CIA) in order to demonstrate the issues 
which are found more critical based on user statements (Kuru, 2015). Conceptual or cognitive maps can also be used to represent concepts and their relations (Farsides, 2004).

Models can also represent experience over time by focusing on the temporality of the experience and how it evolves over a given period of time (Karapanos, Zimmerman, Forlizzi \& Martens, 2009). Longitudinal ethnographic studies such as diaries focus on temporal changes of an investigated experience by methods such as UX Curve (Kujala, Roto, Väänänen-Vainio-Mattila, Karapanos \& Sinnelä, 2011), and are powerful to achieve models representing experience over time. Finally, as a rather direct approach, models can be used to represent design recommendations, either by being integrated into mental models (Young, 2008) or as infographics. Design recommendations can be fed from a broad array of UXR methods.

After this brief introduction, the following section presents our approach to integrate UX modelling in an educational context and dwells on the aforementioned UX models and matching UXR methods in detail, with illustrations from the outputs by sample student projects.

\section{UX Modelling as an Educational Approach}

We devised a graduate level industrial design course, which is structured around UX modelling and aims to allow students acquire hands-on skills in planning, conducting, analysing and communicating UXR. As effective modelling requires mastery in selecting and applying appropriate research methods, course objectives involve raising awareness towards contemporary issues in UX and variety of UXR methods, and obtaining skills to independently plan, research, analyse and model UX. In this section, we first introduce how we guide students in developing UX models and then present typical examples for resulting models from student projects.

\subsection{Developing UX Models: The Course Structure ${ }^{2}$}

The course structure consists of a combination of lectures, assignments and class workshops distributed over fourteen weeks. Lectures include UX concepts and models, a comprehensive list of UXR methods, use of research equipment, data analysis and data visualisation. Parallel with the lectures, students are guided through a collection of assignments of literature survey on specific UXR methods, planning studies and specifying research protocols, conducting pilot studies, data collection and analysis, and visualisation of the findings. Aligned with this process structured by the lectures and assignments, class workshops are organised on categorising UXR methods, data coding, data visualisation and peer evaluation. Workshops both help fostering the theoretical knowledge and practical skills obtained from lectures and assignments, and encourage peer learning as each UXR case involves using different UXR methods and visualisation techniques. Students work either alone or as pairs on subjects (experiences) of their choice, and the course is concluded with a poster design for each project, which is discussed and assessed in a final jury and exhibition.

During the course, around 60 methods, techniques and tools for UXR are presented to students by grouping them under six major categories, namely survey methods, interview methods, observation methods, diary methods, workshop methods, and expert evaluation methods. Students are expected to choose two of them and compile a UXR project based on their interest areas. Each project is supervised by the course team through the aforementioned assignments and workshops. After the data collection phase, students are lectured on types of UX models introduced in Section 3 and they are asked to select an appropriate model and apply it for their projects.

The course has been offered and completed for two semesters and is currently on its third semester. A total of twenty-one graduate students have completed the course so far, and twelve different UXR cases have been worked on as separate projects. These twelve projects, resulting UX models and matching UXR methods employed in these cases are presented in Figure 1.

\footnotetext{
${ }^{2}$ A more detailed procedure of the course is presented in Töre Yargın, Süner and Günay (2018).
} 
MODELS AND MITHODS

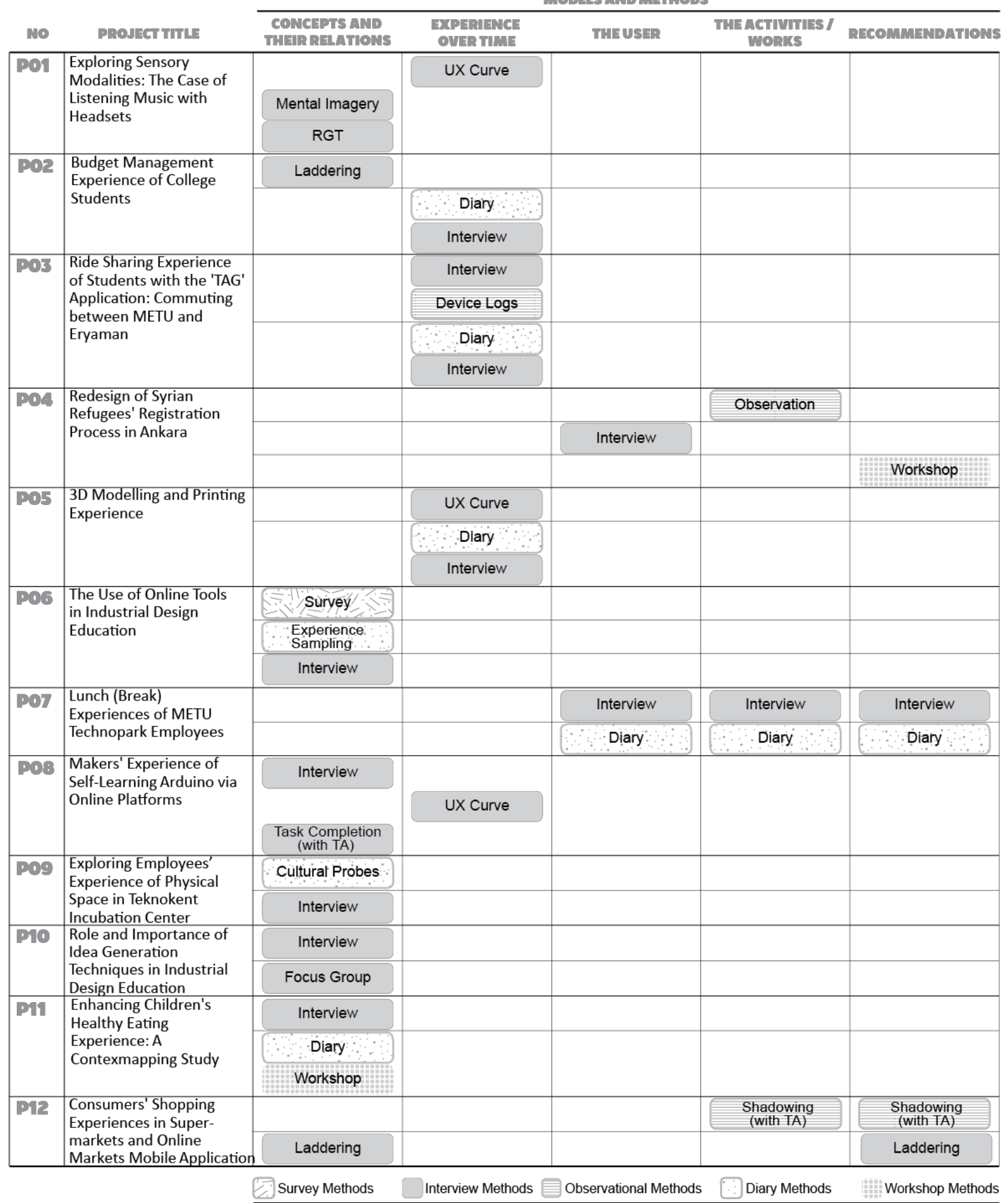

Figure 1. Summary of all projects conducted throughout the two semesters of the course. Each project is given a code, as identified in the first column. Students who conducted the projects: P01: Semih Danış, Ali Al Samarei; P02: Emre Çağlar, Mert Kulaksız; P03: Yavuz Paksoy, Mehmet Erdi Özgürlük; P04: Betül Gültekin, Mert Tosun; P05: Merve Erman, Azra Süngü; P06:

Özümcan Demir, Itır Güngör Boncukçu; P07: Zeynep Yalman, Gizem Cürdaneli; P08: Aslıhan Tokat; P09: Ayşegül Kaya, Yashar Kardar; P10: Milad Hajiamiri; P11: Sıla Umulu; P12: Doğa Balkanlı; Yağmur Merve Arık

\subsection{UXR Methods Applied in Students Projects}

As seen in Figure 1, there was an array of methods applied by the students including interview methods, such as traditional interviews and focus groups, laddering (Reynolds \& Olson, 2001), repertory grid (Fransella, Bell \& Bannister, 2004) and UX Curve interviews (Kujala et al., 2011); observational methods, such as naturalistic observation, shadowing and collecting device logs to observe behaviour; diary methods, such as traditional diaries, 
experience sampling (Hektner, Schmidt \& Csikszentmihalyi, 2007) and cultural probes (Gaver, Dunne \& Pancetti, 1999); and workshop methods conducted with users and designers. In order to understand and model the experience, for each project, different methods were selected to plan a multi-stage study. Figure 2 demonstrates graphics that explain methodological stages for some of the projects. Although, for each project, usually two or three methods were selected, additional stages such as screening surveys, pilot study sessions and complementary interviews were necessary and involved in the figure. Having such diversity in the methods applied during the projects enabled the students to triangulate data, thereby enrich their views while modelling the experience more holistically.

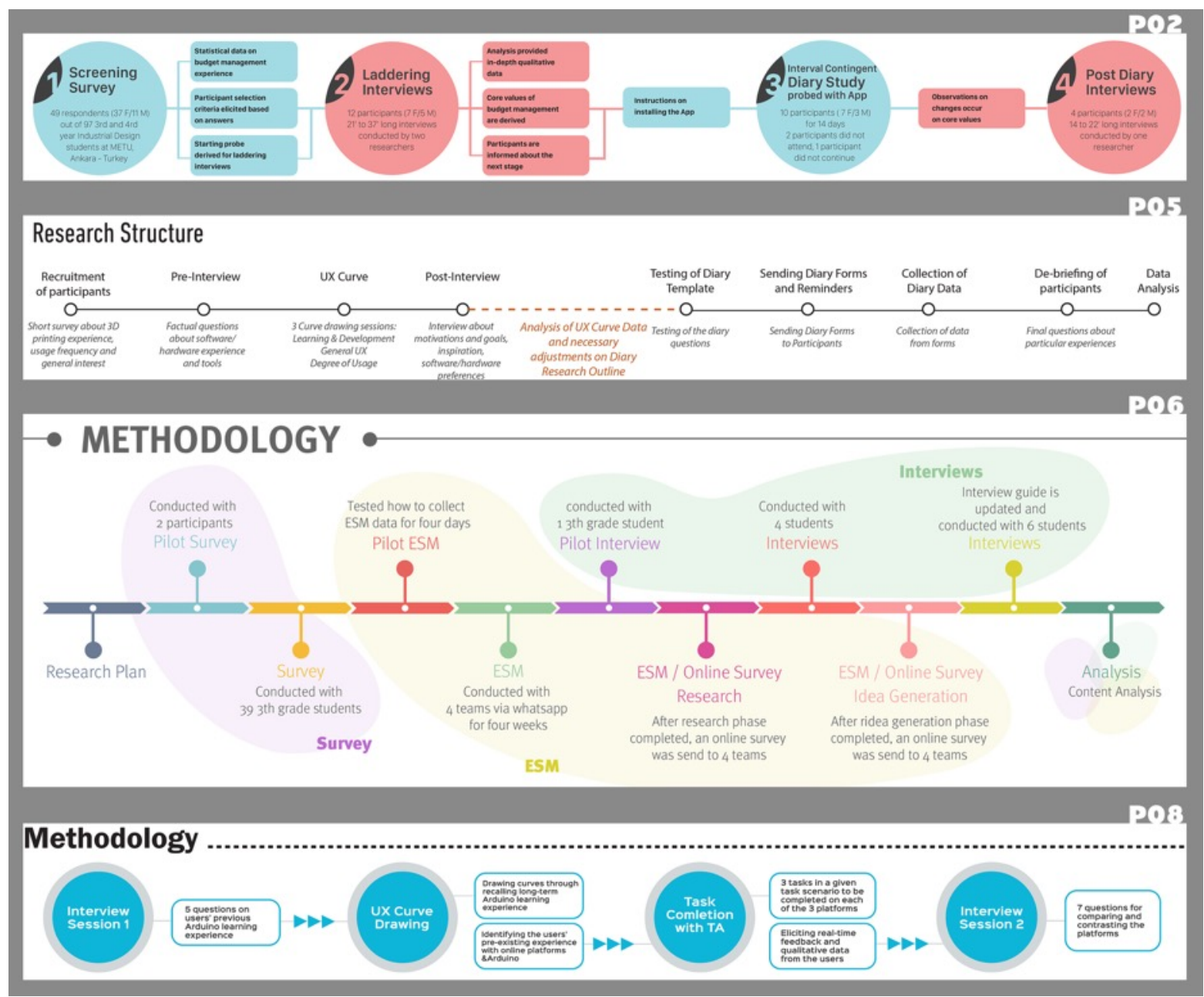

Figure 2. Examples of methodological stages defined in the student projects

When the overall projects are considered (Figure 1), most of them involved eliciting user attitudes and behaviours through interviews, observations and diaries, although two studies went further on collecting additional imaginative knowledge through workshops with designers and users. In the first case (P04), insights through observations and interviews were generated regarding Syrian refugees' concerns and experiences related to the registration process to official services, and then a generative workshop with designers was conducted with the purpose of developing innovative solutions based on those insights. For the second case (P11), within the scope of a study on enhancing children's healthy eating habits, a generative workshop with children was carried out to understand children's dreams and expectations on the subject following interviews with parents and a diary study with children.

For some of the cases, there were concrete products or services to be evaluated (e.g. headsets in P01, mobile apps for budget management in P02, car sharing in P03, online learning platforms in P08, and online shopping in P12), whereas for others, there were only experiences to focus on without any mediating product or system related to the experience (e.g. lunch break in P07, registration process of the refugees in P04, children's healthy eating habits in P11, and using idea generation techniques in design education in P10). Additionally, the variety in UXR methods used in a single research case also allowed the generation of multiple UX models where applicable. 


\subsection{Modelling Approaches Adopted in Student Projects}

For each project, UX models were generated representing concepts and their relations, experience over time, activities or works, the user, and design recommendations. In this section, how these models were generated is briefly discussed together with example models from student projects.

\subsubsection{Representing Concepts and Their Relations}

The most common modelling approach preferred by the students is representing concepts and their relations. During the course, students were expected to conduct qualitative research and apply content analysis (Miles, Huberman \& Saldana, 2014) to interpret data, which resulted in identifying important concepts related to the needs, expectations, concerns, perceptions and habits of the users, and relations between these concepts. Such analysis can constitute valuable input for the design process, since becoming aware of these concepts enables a designer to understand the user and their context, and hence, design products which are meaningful for the target group. To generate models focusing on concepts and their relations, mostly interview methods, which rely on collecting attitudinal data, were selected (Figure 1). Moreover, diary studies including experience sampling and cultural probes accompanied by postinterviews facilitated identification of these concepts and relations by providing in-depth data about user experience. Figure 3 illustrates two examples for such models. The first one (P02) focuses on motivations, strategies and challenges of budget management and how they are related to personal values as a result of the laddering interviews with undergraduate students. The second (P06) represents expected qualities of online tools that support the design process and facilitate teamwork in studio education, exemplified with participant comments.

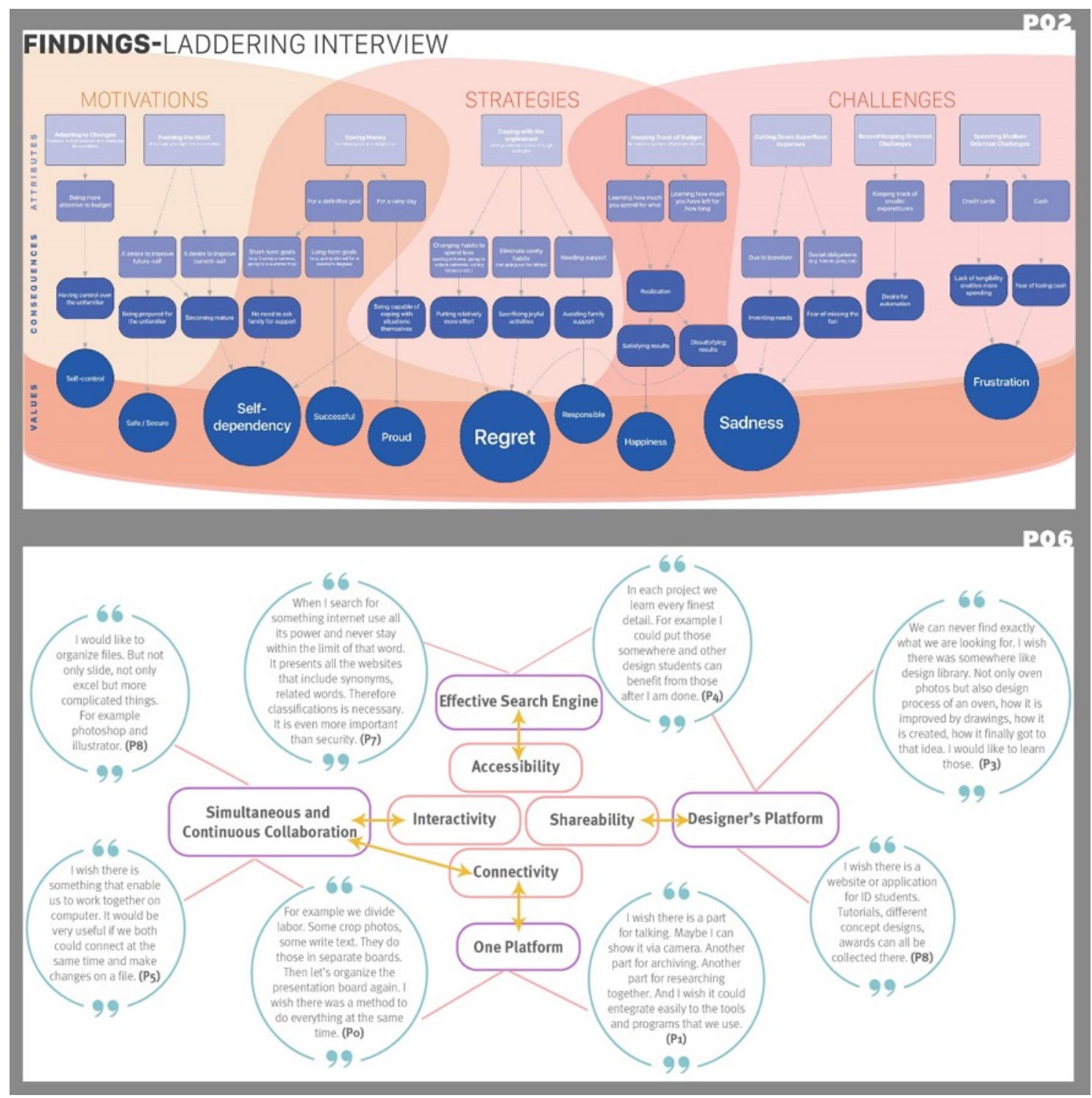

Figure 3. Models representing concepts and their relations (top: Hierarchical Value Map in P02; bottom: Conceptual Map in P06) 


\subsubsection{Representing Experience over Time}

Representing UX over time is the second common modelling aim found in the course outputs. Beyond the momentary experience, how products are experienced by users throughout their lifecycle has been an important topic for UXR. To represent experience over time, students collected data through longitudinal studies involving diaries and device logs, and retrospective interviews including a UX Curve activity, which aims to understand key events and components of the previous experience with a certain product or a service. Figure 4 includes two different models in the form of experience maps; one of which (P05) illustrates stages of makers' 3D modelling and printing experience and their concerns and strategies related to these stages based on a diary study. The second one (P08) is aligned with a conceptual map demonstrating important constructs of self-learning experience with Arduino through online learning platforms. The map demonstrates stages of self-learning and concepts related to each stage derived from the data elicited through a UX Curve activity.
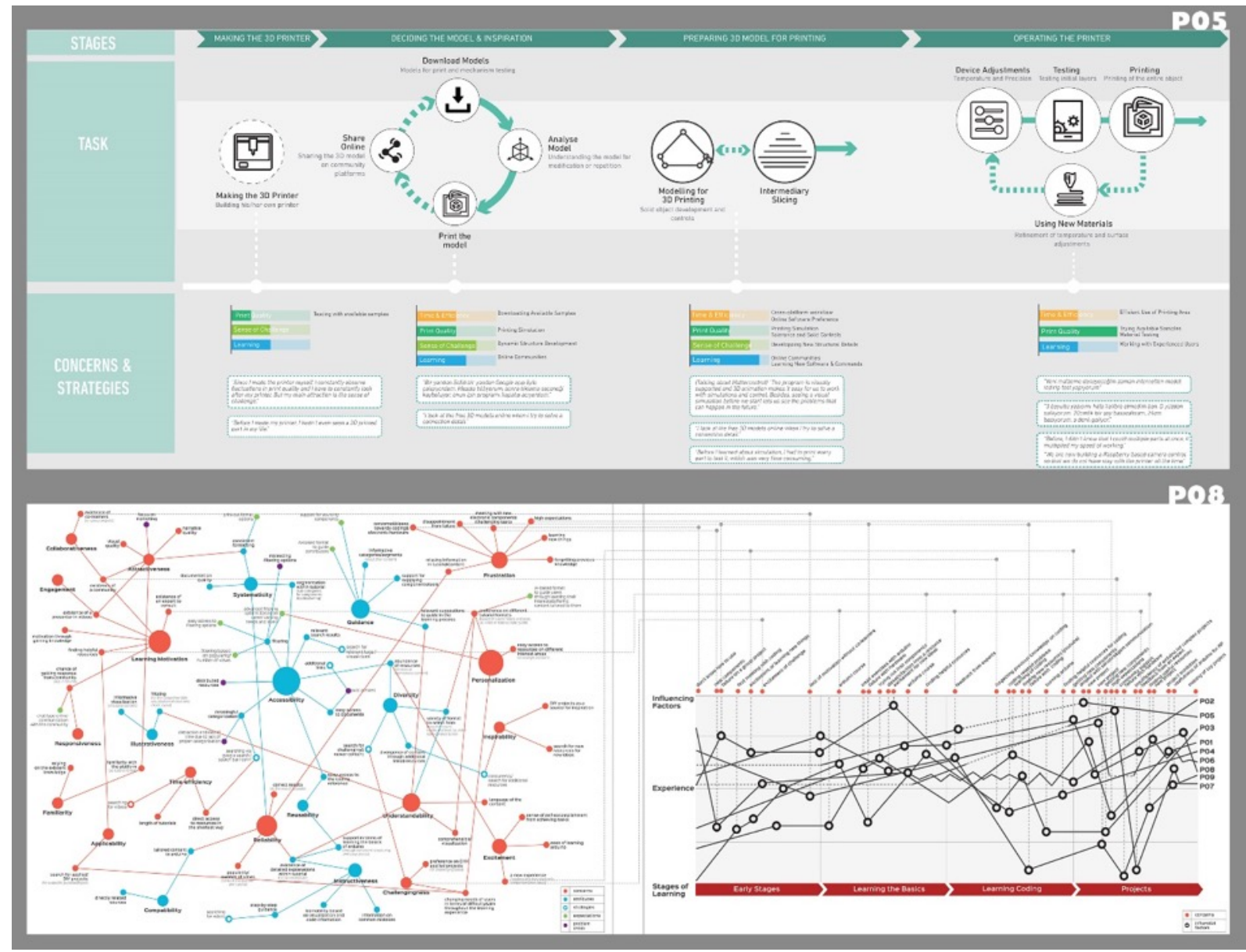

Figure 4. Models representing UX over time (top: Experience Map in P05; bottom: Conceptual Map and related Experience Map in P08)

\subsubsection{Representing the User}

As an outcome of UXR, typical users can be characterized and personified with the purpose of building empathy in the design process. Both attitudinal and behavioural data can be used to generate such user representations. Figure 5 illustrates two different types of personas resulting from the student projects. In the first one (P07), personas with different motivational orientations were developed based on lunch break experiences of science park employees. In the second one (P04), experiences and backgrounds of Syrian refugees related to the registration process for the official services were represented to be used in the following generative workshop with designers. 


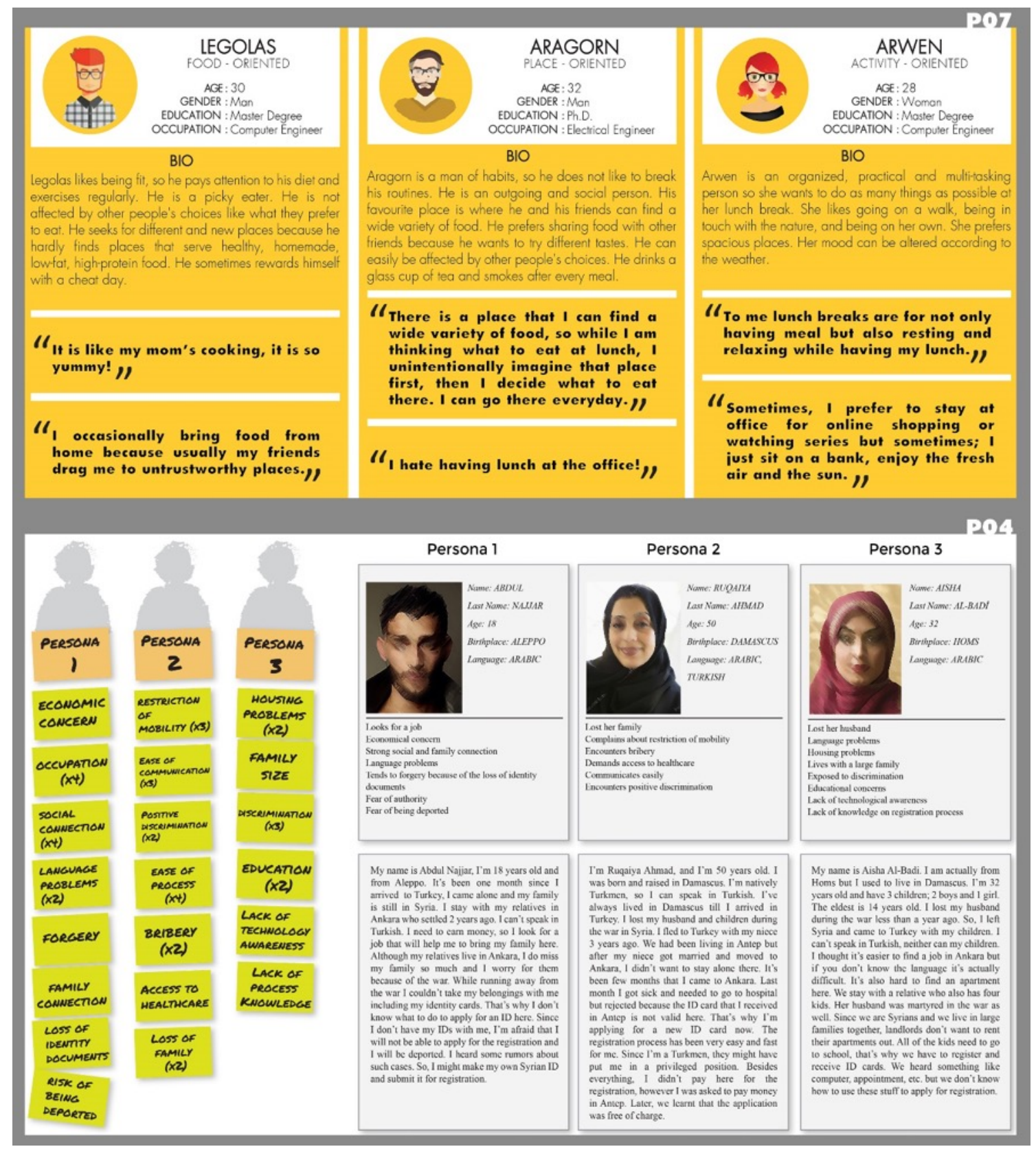

Figure 5. Models representing the user (Personas in P07 and P04)

\subsubsection{Representing the Activities or Works of the User}

Representing the sequential process and activities of users can be helpful when there is a need for developing use case scenarios for a product or system. To understand such activities and processes, it may be necessary to collect behavioural data through observations or interviews on the user's current habits and behaviours. In Figure 6 , the first model (P07) represents science park employees' decision-making processes while planning their lunch break. Based on this model, the students proposed a mobile application design focusing on supporting this decision-making process and the model was contemplated while developing the use scenario for the application. The second model (P04) focuses on refugee registration process based on observations in the migration office, which enabled the students to generate insights related to the current process and identify the possibilities for idealised scenarios. 


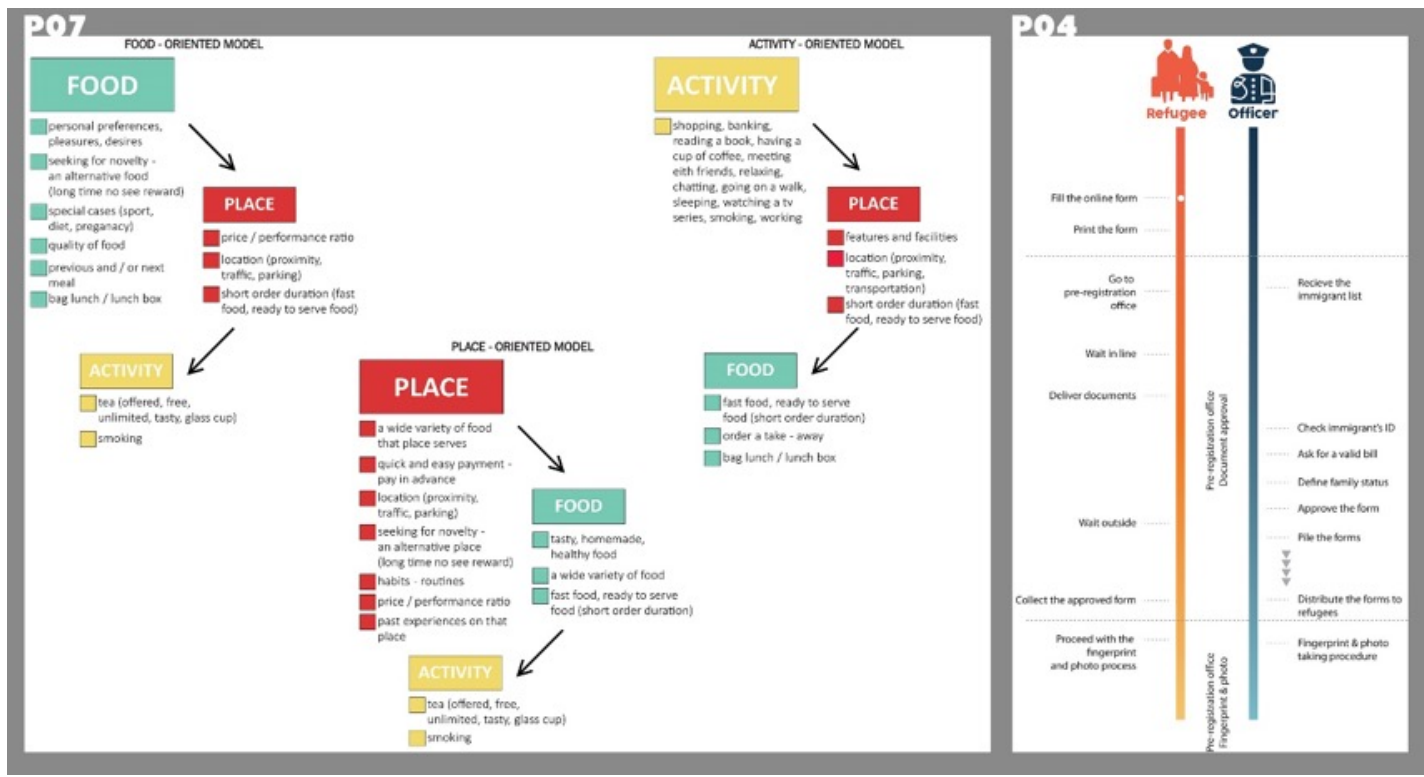

Figure 6. Models representing activities of users (left: Decision Making Process Model in P07; right: Registration Process Model in P04)

\subsubsection{Representing Recommendations}

To specify future directions based on user insights generated through UXR, visual representation can be functional in terms of communicating the recommendations effectively. In order to generate recommendations, designer workshops, where the research outputs are used to guide designers, can be considered as in P04. There were three projects where recommendations were proposed and modelled based on research outcomes. Figure 7 delivers two of them, first of which (P04) focuses on designer workshop outcomes aiming to improve refugees' registration process, whereas the second one (P12) highlights the areas open for improvement for mobile shopping applications and supermarkets based on laddering interview and shadowing data.

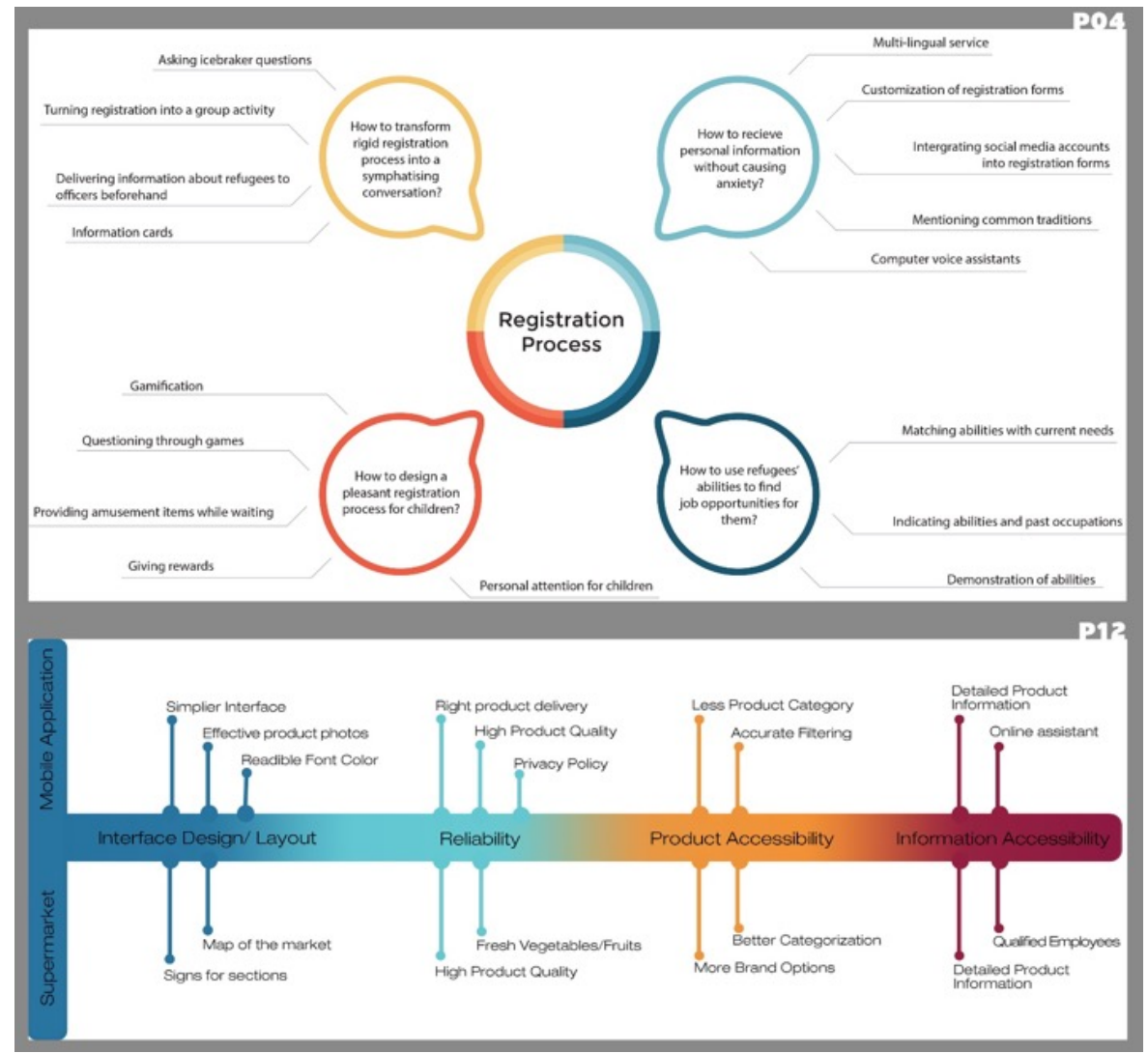

Figure 7. Models representing recommendations (top: Recommendations for refugee registration process in P04; bottom: Recommendations for mobile shopping app in P08) 


\section{Discussion}

Based on the course outputs and our observations during the course, we see that UX modelling in student projects functioned in three ways; (i) making sense of the experience, (ii) enabling effective communication of research insights, and (iii) effortless transference of these insights into actionable design requirements (Figure 8).

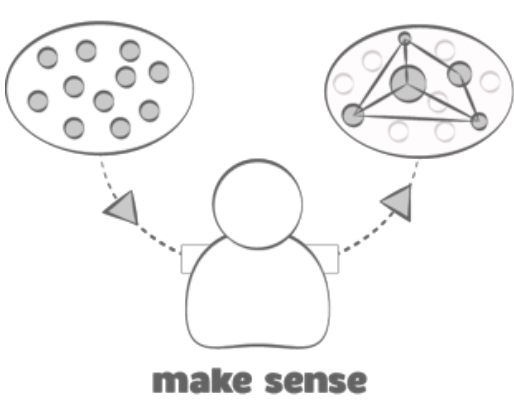

make sense

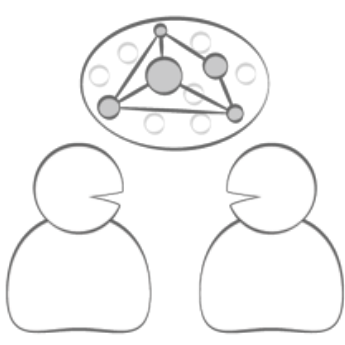

communicate

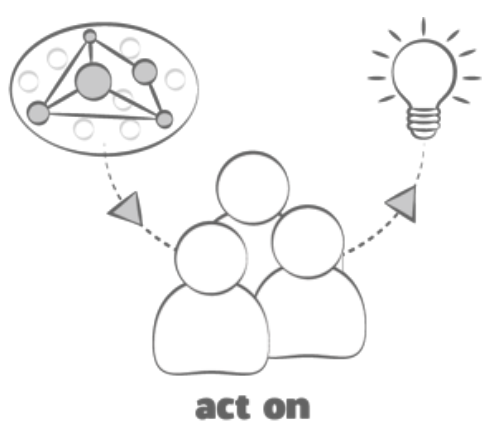

act on

Figure 8. Three functions of UX modelling

First, modelling is a process involving prioritisation and organisation of complex data in a way that is more graspable. It guides the interpreter to discover the relationships between different concepts, patterns of elements (i.e. user behaviours or concerns) and impacts of various factors holistically in a systemic manner. This process naturally involves elimination and prioritisation among pieces of information available in the data, based on judgements about their relevance to the issue at hand (Deutsch, 1952). All these decisions are highly important for forming an estimate of the relevant experience and empathizing with the user.

It goes without saying that all types of models aim for purifying the complexity in examined phenomenon to make sense out of it; yet, especially during the investigation of processes and behaviours that are also highly unfamiliar to the researcher, models can be useful firstly to help the researcher in learning about the existing situation. For instance, Registration Process Model in P04 (Figure 6) was developed initially to capture the essence of the registration processes of Syrian Refugees in Turkey by the students themselves, before proceeding to the next phases in their research.

Apart from being a medium to step into a stranger topic to the researcher, some models are helpful in exploration. The Conceptual Map, and related temporal Experience Map in P08 (Figure 4), have such a function by exploring the contents of and links between experience concepts and process. Even though this hybrid model is not conclusive and might be difficult for direct inferences, it is highly informative to be an exploration medium for a researcher, the next step of which can be identifying patterns.

Secondly, once the experience is modelled, it is no longer confined to the individual mind; it is now internalized, synthesized, yet consolidated; thus, ready to be shared with others. Effective communication of the research findings is a critical issue within organisations (Töre Yargın \& Erbuğ, 2017). Since a model is a visual deliverable, it helps build a shared understanding and collective knowledge; hence, provides transparency within organisations and stakeholders, and supports team collaboration. It not only allows the transference of knowledge derived from UXR, but also mediates formation of new knowledge through collective discussions and reflections.

Again, all models harbour this aim, i.e. delivering the information. Considering the audience of the models and the format in which the models deliver the information, models representing the concepts and their relations as in Hierarchical Value Map in P02 (Figure 3) can communicate manifold concepts related to the perceptions of the users in a well-founded frame. Also, these conceptual maps can be enriched and concretised by verbal anecdotes from users, as in Conceptual Map of P06 (Figure 3), making them more meaningful for the audience. Besides, personas are utilised in P04 to communicate user types and concerns to the design team, and in P07 to guide and justify the design of suggested interface design (Figure5).

Finally, modelling can serve as a bridge between the phases where user insights are generated and where those insights are used to design products/services/systems. The predictive feature of a model aids interpreting and pinpointing potential issues for design intervention. This is not merely the result of the model, as both making sense (analysis) of the data and communication (collective interpretation) involve a somewhat prioritisation process by 
eliminating certain issues whereas focusing on others. In this sense, modelling as a process, together with the model as its product, is a continuous progression from structuring the problem space towards building the solution space. In the course, all models involving recommendations, even if they appear in different levels and fidelity, are important to act on.

As can be seen from the exemplified cases, the students accomplished applying the models, aligning with the three modelling functions identified in this paper: make sense, communicate, and act on. Although the course we outline here is offered as a graduate course opened to students from multiple disciplines, our students mostly have bachelor's degrees in industrial design. This warrants that most of them have prior experience in applying user research for their design studio projects to different extents. Accordingly, design students typically practice integrating user insights to the design process in undergraduate education; however, externalizing such processes and communicating the outcomes of their user research are not usually something they elaborate on during their education, though it can contribute well to their skillsets in practice. The major premise of this course, which is teaching UX modelling, and enabling students to experience these three modelling functions, can empower the students in externalizing-in addition to internalising-user insight generation and integration processes, which would hopefully make them be more equipped as future practitioners.

\section{Conclusion}

This paper presents a teaching approach for equipping design students with the theoretical and applied knowledge and skills relevant in UX projects. Our approach for design education has been driven by the need for fully fledged UX designers in industry, which is hardly achieved with traditional design curriculums that are not specifically developed for training UX designers and researchers.

Models, which own a central importance in science involving a wide range of connotations from physical and fictional objects to equations, have been utilised for analysing, teaching and presenting scientific data, meanwhile allowing to focus on major blocks of the reach topic. In view of these benefits, models can be adopted in UX, as experiences are intrinsically multidimensional, dynamic and complex in nature. Different types of models and matching UXR methods from outputs of our students' projects underpin our inference of major roles of modelling in UX. Apart from their main functions discussed in this paper, models may also influence the selection and construction of opportune research methodology to investigate a certain experience.

The limitations of this paper are based on its seemingly descriptive representation of modelling UX. As these are preliminary steps for drawing up such an educational approach on UX, the effectiveness of diverse models and the modelling approach in UX are continued to be explored and evaluated. It is also important to note that the course is being iteratively updated since both theory and practice of UX are in constant change.

Future work will focus on students' evaluations of the course in order to improve the content and execution, as well as an investigation of the needs and experiences of designers employed in UX professions to develop comprehensive educational strategies for integrating UX-relevant knowledge and skills into design education.

Acknowledgements: The course presented in this paper was designed as part of a research project funded by Middle East Technical University (Project number BAP-08-11-2017-008). We would like to thank all of the students who participated in our course, which is offered at Middle East Technical University, Department of Industrial Design.

\section{References}

Bødker, S., \& Klokmose, C.N. (2012). Preparing students for (inter-)action with activity theory. International Journal of Design, 6(3), 99-111.

Budd, J., \& Wang, W. (2017) Industrial design education: Taming technology to enhance user experience. Archives of Design Research, 30(3), 17-27.

Caws, P. (1974). Operational, Representational, and Explanatory Models. American Anthropologist, 76(1), 1-10.

Churchill, E.F., Bowser, A., \& Preece, J. (2016). The future of $\mathrm{HCl}$ education: A flexible, global, living curriculum. Interactions, 23(2), 70-73.

Deutsch, K.W. (1952). On communication models in the social sciences. Public Opinion Quarterly, 16(3), $356-380$.

Faiola, A. (2007). The design enterprise: Rethinking the $\mathrm{HCl}$ education paradigm. Design Issues, 23(3), 30-45. 
Faiola, A., \& Matei, S.A. (2010). Enhancing human-computer interaction design education: Teaching affordance design for emerging mobile devices. International Journal of Technology and Design Education, 20(3), 239-254.

Farsides, T. (2004). Cognitive mapping: Generating theories of psychological phenomena from verbal accounts and presenting them diagrammatically. In G.M. Breakwell (Ed.), Doing Social Psychology Research (pp. 255-288). Oxford: Blackwell Publishing.

Fransella, F., Bell, R., \& Bannister, D. (2004). A manual for Repertory Grid Technique (2nd ed). Chichester, West Sussex, England; Hoboken, NJ: John Wiley \& Sons.

Frigg, R., \& Hartmann, S. (2018). Models in Science. In E.N. Zalta (Ed.), Stanford Encyclopedia of Philosophy. Stanford, CA: Stanford University.

Fulton Suri, J. (2003). The experience of evolution: Developments in design practice. The Design Journal, 6(2), 39-48.

Gaver, B., Dunne, T., \& Pacenti, E. (1999). Design: Cultural probes. Interactions, 6(1), 21-29.

Getto, G., \& Beecher, F. (2016). Toward a Model of UX Education: Training UX Designers within the Academy. IEEE Transactions on Professional Communication, 59(2), 153-164.

Getto, G., Potts, L., \& Salvo, M.J. (2013). Teaching UX: Designing Programs to Train the Next Generation of UX Experts. Proceedings of the ACM Conference on the Design of Communication (pp. 65-69). Greenville, USA, 30 September-1 October. New York: ACM.

Getto, G., Thompson, R.J., \& Saggi, K. (2016). Spurring UX innovation in academia through lean research and teaching. Proceedings of the IEEE International Professional Communication Conference (IPCC). Austin, TX, USA, 2-5 October 2016.

Giere, R.N. (1999). Using Models to Represent Reality. In L. Magnani, N.J. Nersessian, \& P. Thagard (Eds.), ModelBased Reasoning in Scientific Discovery. Boston: Springer, Boston.

Gilbert, J.K. (2005). Visualization: A metacognitive skill in science and science education. In J.K. Gilbert (Ed.), Visualization in Science Education. Netherlands: Springer.

Gilbert, S.W. (1991). Model building and a definition of science. Journal of Research in Science Teaching, 28(1), 73-79.

Gonzalez, C.A., Smith, M.A., \& Youmans, R.J. (2017). Are human factors students prepared for careers in user experience research? A survey of predicted and actual skill utilization. Proceedings of the Human Factors and Ergonomics Society 2017 Annual Meeting, 61(1), 1101-1105.

Hanington, B.M. (2010). Relevant and rigorous: Human-centered research and design education. Design Issues, 26(3), 18-26.

Hanington, B., \& Martin, B. (2012). Universal Methods of Design: 100 Ways to Research Complex Problems, Develop Innovative Ideas, and Design Effective Solutions. Rockport, MA: Rockport Publishers.

Hassenzahl, M., \& Tractinsky, N. (2006). User experience - a research agenda. Behaviour \& Information Technology, 25(2), 91-97.

Hektner, J.M., Schmidt, J.A., \& Csikszentmihalyi, M. (2007). Experience Sampling Method: Measuring the Quality of Everyday Life. USA: Sage.

Holtzblatt, K., Wendell, J.B., \& Wood, S. (2004). Rapid contextual design: A how-to guide to key techniques for usercentered design. San Francisco: Morgan Kaufmann.

Jordan, P.W. (1999). Pleasure with products: human factors for body, mind and soul. In W.S. Green \& P.W. Jordan (Eds.), Human factors in product design: Current practice and future trends. London: Taylor and Francis.

Karapanos, E., Zimmerman, J., Forlizzi, J., \& Martens, J.-B. (2009). User experience over time: an initial framework. Proceedings of SIGCHI Conference on Human Factors in Computing Systems. Boston, 4-9 April. New York: ACM.

Kujala, S., Roto, V., Väänänen-Vainio-Mattila, K., Karapanos, E., \& Sinnelä, A. (2011). UX Curve: A method for evaluating long-term user experience. Interacting with Computers, 23(5), 473-483.

Kuru, A. (2015). Cross impact analysis: An alternative way of qualitative data analysis of repertory grid technique. Journal of Design Research, 13(4), 362-380.

Law, E. L.-C., \& van Schaik, P. (2010). Modelling user experience - an agenda for research and practice. Interacting with Computers, 22(5), 313-322.

Miles, M.B., Huberman, A.M., \& Saldana, J. (2014). Qualitative Data Analysis: A Methods Sourcebook (3 ${ }^{\text {rd }}$ ed.). Thousand Oaks, CA: Sage.

Miles, S., \& Rowe, G. (2004). The Laddering Technique. In G.M. Breakwell (Ed.), Doing Social Psychology Research (pp. 305-343). Oxford: Blackwell Publishing.

Pruitt, J., \& Adlin, T. (2006). The Persona Lifecycle: Keeping People in Mind Throughout Product Design. Oxford: Elsevier.

Reynolds, T.J., \& Olson, J.C. (2001). Understanding consumer decision making: The means-end approach to marketing and advertising strategy. New Jersey: Lawrence Erlbaum.

Töre Yargın, G., \& Erbuğ, Ç. (2017). Inspiration, Guidance and Justification: An Interactive Information System to Assist Design Decisions with User Research Data. METU Journal of the Faculty of Architecture, 34(2), 13-33. 
Töre Yargın, G., Süner, S. \& Günay, A. (2018). Modelling User Experience: Integrating User Experience Research into Design Education. In K. Blashki \& Y. Xiao (Eds.), Proceedings of the IADIS International Conferences Interfaces and Human Computer Interaction (pp. 26-34). Madrid, 17-20 July 2018. IADIS Press.

Young, I. (2008). Mental Models: Aligning Design Strategy with Human Behavior. New York: Rosenfeld.

\section{About the Authors}

Gülşen Töre Yargın is an assistant professor at METU, Department of Industrial Design and director of UTEST Product Usability Unit. After completing her PhD on effective communication of user research knowledge to design process, she conducted post-doctoral studies at University of Cambridge. Her current interests focus on UXR methods and education and identifying user-centred use cases for emerging technologies.

Aslı Günay is a post-doctoral researcher at University of Cambridge, Engineering Design Centre, Healthcare Design Group and a senior user experience (UX) researcher at UTEST Product Usability Unit. Having completed her PhD on UX with mobile health technologies for pregnancy and their effects on well-being, her interests focus on UX, design for well-being, digital health, UXR methods, and UX education.

Sedef Süner-Pla-Cerdà is an assistant professor of industrial design at TED University. Having obtained her PhD in industrial design, her research and teaching interests focus on research methods with child-users, user-centred design, methods of user research, and integration of user-centred methods into design education. 